\title{
Design, Synthesis and Evaluation of Novel N-Substituted-[Benzoylamino]-5-Ethyl-1,2,3,6- Tetrahydropyridines as Potential Anti-Cancer Agents
}

\author{
Elizabeth D Henderson, Madhavi Gangapuram, Suresh Kumar VK Eyunni, Kinfe K Redda and Tiffany Wilson-Ardley
} College of Pharmacy and Pharmaceutical Sciences, Florida A \& M University, Tallahassee, FL, USA

Article Info
*Corresponding author:
Tiffany Wilson-Ardley
College of Pharmacy and Pharmaceutical
Sciences
Florida A \& M University
USA
Tel: (850) 599-3774
Fax: (850) 561-2038
E-mail: tiffany.ardley@famu.edu

Received: October 2, 2018

Accepted: February 22, 2019

Published: March 4, 2019

Citation: Henderson ED, Gangapuram M, Eyunni SV, Redda KK, Wilson-Ardley T. Design, Synthesis and Evaluation of Novel $\mathrm{N}$-Substituted-[Benzoylamino]-5-Ethyl1,2,3,6-Tetrahydropyridines as Potential Anti-Cancer Agents. Madridge J Pharm Res. 2019; 3(1): 52-59.

doi: 10.18689/mjpr-1000109

Copyright: ( $\odot 2019$ The Author(s). This work is licensed under a Creative Commons Attribution 4.0 International License, which permits unrestricted use, distribution, and reproduction in any medium, provided the original work is properly cited.

Published by Madridge Publishers

\begin{abstract}
Background and Objective: Inflammation is believed to incite carcinogenesis by causing cell and genome damage. Tetrahydropyridines have gained significant synthetic interest because they constitute biologically active features of pharmaceutical agents. Previous tetrahydropyridines developed by our research group were effective in inhibiting inflammation. Since there is a relationship between inflammation and cancer, the objective of this manuscript is to expand our prior study to determine the anti-cancer activity of novel tetrahydropyridine analogs.
\end{abstract}

Materials and methods: 3 -Ethylpyridine reacted with O-mesitylenesulfonylhydroxylamine to furnish $\mathrm{N}$-amino-3-ethylpyridinium mesitylenesulfonate. The reaction of $\mathrm{N}$-amino-3ethylpyridinium mesitylenesulfonate with substituted acid chlorides gives the stable crystalline pyridinium ylides. A sodium borohydride reduction of ylides furnishes the target compounds, $\mathrm{N}$-substituted [benzoylamino]-5-ethyl-1,2,3,6-tetrahydropyridines. The evaluation of these analogs cytotoxicity against Ishikawa, MCF-7, and MDA-MB-231 cell lines were determined after 72 hours of drug exposure employing CellTiter-Glo assay. To explore the interaction between the tetrahydropyridine derivatives and estrogen receptor alpha, SYBYL-X 2.1 was used to determine the best bioactive conformations of the tetrahydropyridine derivatives for the active site of the receptor.

Results: Four novel N-substituted [benzoylamino]-5-ethyl-1,2,3,6-tetrahydropyridines were synthesized, purified, and characterized. The four tetrahydropyridine analogs exhibited some anti-cancer activity. Based on the molecular modeling studies, EH3 was expected to have the best antiproliferative activity due to having the highest docking score for ER $\alpha$. However, EH2 had the best antiproliferative activity. Nevertheless, the biological screening and molecular modeling can provide insight to help with the design of more biologically active compounds as potential anti-cancer agents.

Keywords: Tetrahydropyridines; Nitrogen ylides; Cancer; Antiproliferative agents; Estrogen receptor alpha.

\section{Abbreviations}

Arg: Arginine; ATP: Adenosine Triphosphate; $\mathrm{CDCl}$ : Deuterium Chloroform; $\mathrm{CH}_{2} \mathrm{Cl}_{2}$ : Dichloromethane; ${ }^{\circ} \mathrm{C}$ : Degrees Celsius; $\mathrm{cm}$ : centimeters; ${ }^{13} \mathrm{C}-\mathrm{NMR}$ : Carbon Nuclear Magnetic Resonance; $\mathrm{CO}_{2}$ : Carbon Dioxide; DMSO: Dimethyl Sulfoxide; ER: Estrogen Receptor; ER $\alpha$ : Estrogen Receptor Alpha; ERß: Estrogen Receptor Beta; Et ${ }_{3} \mathrm{~N}$ : Triethylamine; FTIR: Fourier Transform Infrared Spectroscopy; g: gram; Glu: Glutamic Acid; Gly: Glycine; $\mathrm{HCl}$ : HydrochloricAcid; $\mathrm{HClO}_{4}$ : Perchloric Acid; His: Histidine; ${ }^{1} \mathrm{H}-\mathrm{NMR}$ : Proton Nuclear Magnetic Resonance; $\mathrm{IC}_{50}$ : Inhibitory Concentration of 50\%; IR: Infrared 
Spectroscopy; KBr: Potassium Bromide; MeCN: Acetonitrile; $\mathrm{MeOH}$ : Methanol; $\mathrm{mL}$ : milliliters; mmol: millimole; $\mathrm{MSH}$ : Mesitylenesulfonyl Hydroxamate; $\mathrm{NaHCO}_{3}$ : Sodium Bicarbonate; $\mathrm{Na}_{2} \mathrm{SO}_{4}$ : Sodium Sulfate; $\mathrm{nM}$ : nanomolar; 4-OHT: 4-Hydroxytamoxifen; PBS: Phosphate Buffer Solution; ppm: parts per million; RPMI: Roswell Park Memorial Institute; SERMs: Selective Estrogen Receptor Modulators; TAM: Tamoxifen; THF: Tetrahydrofuran; THP: Tetrahydropyridine; TLC: Thin Layer Chromatography; TMS: Trimethylsilane; $\mu \mathrm{L}$ : microliter; $\mu \mathrm{M}$ : micromolar; UV: Ultraviolet; $\delta$ : Chemical Shift.

\section{Introduction}

Breast cancer is the second leading cause of cancerrelated deaths in women. In 2018, the American Cancer Society estimates that $1,735,350$ new cancer cases were diagnosed in the United States [1]. Approximately $80 \%$ of breast cancers are estrogen receptor positive [2]. Estrogen receptors (ER) are composed of a group of steroidal compounds named for their role in regulating menstruation and reproduction in women [3]. ER is considered a nuclear receptor that plays an important role in the growth of breast tumors. The two types of estrogen receptors are estrogen receptor alpha $(E R \alpha)$ and estrogen receptor beta $(E R \beta)$. ER $\alpha$ is mainly expressed in the mammary gland, uterus, ovary (thecal cells), bone, male reproductive organs (testes and epididymis), prostate (stroma), liver, and adipose tissue [3]. In contrast, ER $\beta$ is predominant in the prostate (epithelium), bladder, ovary (granulosa cells), colon, adipose tissue, and immune system [3]. Estrogen is a hormone produced mainly in the ovaries and is involved in breast cancer cell proliferation. Selective estrogen receptor modulators (SERMs) are various compounds that interact with intracellular estrogen receptors in different target organs as ER agonists or ER antagonists [4]. In order to inhibit the growth of breast cancer cells, antagonists (Tamoxifen) are used to block the estrogen action on tumor cells thereby preventing the binding of estrogen to the ER. Tamoxifen has been the leading drug to treat individuals that are diagnosed with ER-positive breast cancer, but unfortunately the adverse effects are problematic. Therefore, there remains a significant need to develop effective estrogen receptor modulators with less adverse effects.

Tetrahydropyridines (THPs) have gained significant synthetic interest due to possessing biological activity in natural products and pharmaceutical agents [5-10]. In previous papers, our laboratory reported the synthesis and anti-inflammatory activity of several 1,2,3,6-tetrahydropyridines [8,11-18]. Several 1,2,3,6-tetrahydropyridine derivatives have shown that their pharmacological activity depends on the position and nature of the substituents on the THP ring structure [15-17]. Due to the connection between inflammation and cancer, a series of substituted 1,3,4-oxadiazolyl tetrahydropyridines were synthesized [17]. These compounds were found to have moderate cytotoxicity in vitro on MCF-7 breast cancer cell lines. Due to the cytotoxicity on MCF-7 breast cancer cell lines, it is imperative to synthesize and design more tetrahydropyridine analogs that are not toxic.
It has been previously reported that a series of 5-ethyl THPs had anti-inflammatory activity $[10,12]$. The preliminary studies on these compounds also show some anti-cancer properties. Here, we report the anti-cancer activities of four novel 5-ethyl THP derivatives. The different substituents were chosen based on the molecular properties and bioactivity score from Molinspiration Cheminformatics [19]. The structural modifications on the THP moiety will affect the lipophilicity, size, and electron density of the compound which will also affect the activity. The molecular modeling images were generated using OpenEye Scientific Software [20]. These images provided a visual of the best conformation for the tetrahydropyridines and interaction to the active site of ER $\alpha$. This analysis will provide the foundation for future optimization studies of the lead compound.

\section{Materials and Methods}

\section{Synthesis of tetrahydropyridines}

The structures of the ylides and tetrahydropyridines were confirmed by ${ }^{1} \mathrm{H}-\mathrm{NMR},{ }^{13} \mathrm{C}-\mathrm{NMR}$, IR, and elemental analysis. Hydrogen nuclear magnetic resonance spectra ( $1 \mathrm{H}-\mathrm{NMR})$ were determined on a Bruker $\mathrm{HX}-300 \mathrm{MHz}$ spectrometer using $\mathrm{CDCl}_{3}$ as solvent unless otherwise specified. Carbon nuclear magnetic resonance spectra $\left({ }^{13} \mathrm{C}-\mathrm{NMR}\right)$ were determined on a Bruker $\mathrm{HX}-600 \mathrm{MHz}$ spectrometer using $\mathrm{CDCl}_{3}$ as solvent. Chemical shifts $(\delta)$ were reported in parts per million (ppm) downfield from trimethylsilane (TMS) as an internal standard. Fourier transform infrared spectroscopy spectra (FTIR) were ran with potassium bromide $(\mathrm{KBr})$ pellets on the Perkin Elmer Spectrum 100. Elemental Analysis was performed by Atlantic Microlab, Inc. (Norcross, GA). Melting points were determined on an Electro thermal MEL-TEMP 30 melting point apparatus and were uncorrected. Chemicals and solvents were purchased by Sigma-Aldrich Chemical Company (St. Louis, MO). Purification of ylides and tetrahydropyridines were done using flash column chromatography. All reactions and purification procedures were monitored by thin layer chromatography(TLC) on Whatman 60F-245 plates AL SIL g/UV, $250 \mu \mathrm{M}$ layer plates with visualization under ultraviolet(UV) light.

\section{General procedure 1}

Synthesis of $\mathbf{N}$-(1-Naphthoylimino)-3-ethylpyridinium Ylide (8a): Ethyl acetohydroxymate (1) $(10.23 \mathrm{~g}, 99.20 \mathrm{mmol})$ was dissolved in $50 \mathrm{~mL}$ of $\mathrm{N}, \mathrm{N}$-dimethylformamide at $0^{\circ} \mathrm{C}$. Fifteen minutes later, mesitylene sulfonyl chloride (2) $(21.70 \mathrm{~g}, 99.20$ $\mathrm{mmol}$ ) was slowly added along with $0.75 \mathrm{~mL}$ of triethylamine $\left(E t_{3} N\right)$. The solution stirred at ice bath temperature for fortyfive minutes. After forty-five minutes, the reaction was poured over ice and a yellow precipitate formed. After the mixture came to room temperature, the solid, ethyl O-(mesitylenesulfonyl) acetohydroxamate (3) was collected by vacuum filtration. Ethyl O-(mesitylenesulfonyl) acetohydroxamate (3) (13.12 g, $45.98 \mathrm{mmol}$ ) was washed three times with $100 \mathrm{~mL}$ of distilled water and air dried for one hour. The product (3) was hydrolyzed with $70 \%$ perchloric acid $\left(\mathrm{HClO}_{4}\right)(4 \mathrm{~mL})$ in $p$-dioxane: water 
$(4: 1 \mathrm{v} / \mathrm{v})$. This reaction stirred for forty-five minutes at $0^{\circ} \mathrm{C}$. The reaction was arrested by the addition of ice and an off white solid, mesitylenesulfonyl hydroxamate (MSH) (4) [21,22] was collected by vacuum filtration and allowed to air dry for thirty minutes. MSH $(9.00 \mathrm{~g}, 41.86 \mathrm{mmol})$ was dissolved in $30 \mathrm{~mL}$ of dichloromethane $\left(\mathrm{CH}_{2} \mathrm{Cl}_{2}\right)$. The reaction stirred at $0^{\circ} \mathrm{C}$ for fifteen minutes before 3-ethylpyridine (5) $(4.70 \mathrm{~mL}, 41.86$ mmol) was added drop wise. The mixture reacted for fortyfive minutes at $0^{\circ} \mathrm{C}$. After forty-five minutes, the 3-ethylpyridinium mesitylenesulfonate (6) was extracted with $100 \mathrm{~mL}$ of diethyl ether.

3-ethylpyridinium mesitylenesulfonate (6) (4.07 g, 12.56 $\mathrm{mmol}$ ) in $20 \mathrm{~mL}$ of anhydrous tetrahydrofuran (THF) at $70^{\circ} \mathrm{C}$ was stirred for fifteen minutes before 1-naphthoyl chloride (7) $(1.38 \mathrm{~g}, 12.56 \mathrm{mmol})$ was added. The mixture ran overnight at $70^{\circ} \mathrm{C}$. After twenty-four hours, $20 \mathrm{~mL}$ of saturated sodium bicarbonate $\left(\mathrm{NaHCO}_{3}\right)$ arrested the reaction. The product, $\mathrm{N}$-(1-Naphthoylimino)-3-ethylpyridinium ylide (8a) was extracted with $100 \mathrm{~mL}$ of dichloromethane $\left(\mathrm{CH}_{2} \mathrm{Cl}_{2}\right)$ three times and dried over sodium sulfate. The ylide was obtained by filtration and evaporation of the solvent, then purified by flash column chromatography using ethyl acetate: hexane $(6: 4 \mathrm{v} / \mathrm{v})$. General Procedure 1 scheme is shown in figure 1. The result (8a) was a white solid $(0.439 \mathrm{~g}, 30 \%)$; $\mathrm{mp}$ : $162.2-$ 164.5 ${ }^{\circ} \mathrm{C} ;{ }^{1} \mathrm{H}-\mathrm{NMR}\left(300 \mathrm{MHz} \mathrm{CDCl}_{3}\right)(\delta): 1.35(\mathrm{t}, \mathrm{J}=7.8 \mathrm{~Hz}, 3 \mathrm{H}$, $\left.\mathrm{CH}_{2} \mathrm{CH}_{3}\right), 2.81\left(\mathrm{q}, \mathrm{J}=7.6 \mathrm{~Hz}, 2 \mathrm{H}, \mathrm{CH}_{2} \mathrm{CH}_{3}\right), 7.46-7.55(\mathrm{~m}, 2 \mathrm{H}$, $\left.\mathrm{C}_{5^{\prime \prime}} \mathrm{C}_{9^{\prime}}-\mathrm{H}\right), 7.56-7.72\left(\mathrm{~m}, 1 \mathrm{H}, \mathrm{C}_{4^{\prime}}-\mathrm{H}\right), 7.87(\mathrm{dd}, \mathrm{J}=6.9,2.6 \mathrm{~Hz}, 2 \mathrm{H}$, $\left.\mathrm{C}_{5^{\prime}} \mathrm{C}_{6}, \mathrm{H}\right), 8.19\left(\mathrm{dd}, \mathrm{J}=8.7,1.8 \mathrm{~Hz}, 1 \mathrm{H}, \mathrm{C}_{10}, \mathrm{H}\right), 8.26(\mathrm{dd}, \mathrm{J}=8.6$, $\left.1.8 \mathrm{~Hz}, 1 \mathrm{H}, \mathrm{C}_{8^{\prime}}-\mathrm{H}\right), 8.68\left(\mathrm{t}, \mathrm{J}=3.9 \mathrm{~Hz}, 2 \mathrm{H}, \mathrm{C}_{2^{\prime}} \mathrm{C}_{6}-\mathrm{H}\right), 8.79(\mathrm{~s}, 1 \mathrm{H}$, $\left.\mathrm{C}_{3},-\mathrm{H}\right)$. Anal. Calcd. For $\mathrm{C}_{18} \mathrm{H}_{16} \mathrm{~N}_{2} \mathrm{O}$ (276.33): $\mathrm{C}, 78.63 ; \mathrm{H}, 5.82 ; \mathrm{N}$, 8.94. Found: $C, 78.23 ; \mathrm{H}, 5.84 ; \mathrm{N}, 10.14$.

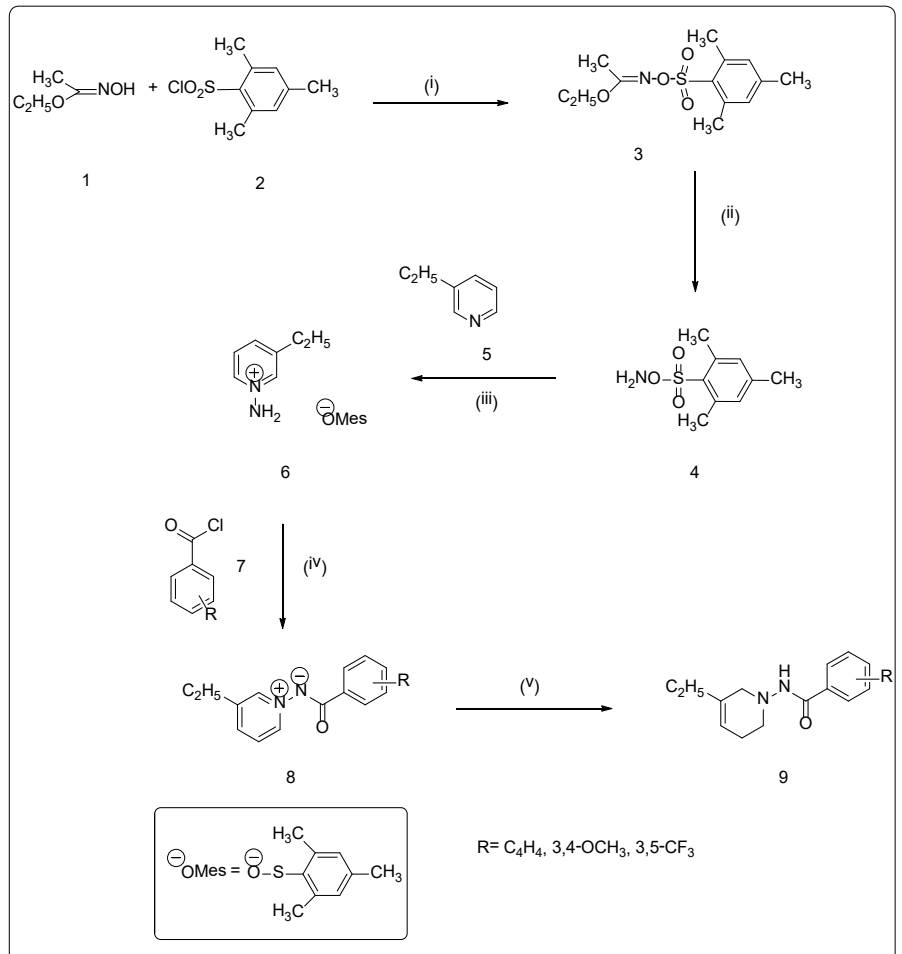

Figure 1. Scheme 1 Reactions and conditions: (i) $\mathrm{DMF}, \mathrm{Et}_{3} \mathrm{~N}, 0{ }^{\circ} \mathrm{C}, 45$ min. (ii) $p$-dioxane $/ \mathrm{H}_{2} \mathrm{O}, 70 \% \mathrm{HClO}_{4^{\prime}} 45 \mathrm{~min}$. (iii) 3-ethylpyridine (5), $\mathrm{CH}_{2} \mathrm{Cl}_{2^{\prime}} 0^{\circ} \mathrm{C}, 45 \mathrm{~min}$. (iv) a.) substituted acyl chlorides (7), $\mathrm{THF}^{\circ} 70^{\circ} \mathrm{C}$, overnight b.) $\mathrm{NaHCO}_{3} / \mathrm{H}_{2} \mathrm{O}$ (v) $\mathrm{NaBH}_{4^{\prime}}$ abs. $\mathrm{EtOH}, 0^{\circ} \mathrm{C}, 7 \mathrm{~h}$.
Synthesis of N-(3,4-Dimethoxybenzoylimino)-3-ethylpyridinium Ylide (8b): 3-ethylpyridinium mesitylenesulfonate (6) $(0.59 \mathrm{~g}$, $1.82 \mathrm{mmol}$ ) in $30 \mathrm{~mL}$ of anhydrous THF at $70^{\circ} \mathrm{C}$ was stirred for fifteen minutes before 3,4-dimethoxybenzoyl chloride (7) $(0.37 \mathrm{~g}, 1.82 \mathrm{mmol})$ was added. The mixture ran overnight. After twenty-four hours, $10 \mathrm{~mL}$ of saturated $\mathrm{NaHCO}_{3}$ arrested the reaction. The product, $\mathrm{N}$-(3,4-dimethoxybenzoylimino)-3ethylpyridinium ylide (8b) was extracted with $100 \mathrm{~mL}$ of $\mathrm{CH}_{2} \mathrm{Cl}_{2}$ three times and dried over sodium sulfate. The ylide was obtained by filtration and evaporation of the solvent, and then purified by flash column chromatography using ethyl acetate: hexane $(6: 4 \mathrm{v} / \mathrm{v})$. The result $(\mathbf{8 b})$ was a white solid $(0.30 \mathrm{~g}, 70 \%)$; mp: $114.3-116.9^{\circ} \mathrm{C} ;{ }^{1} \mathrm{H}-\mathrm{NMR}\left(300 \mathrm{MHz} \mathrm{CDCl}_{3}\right)$

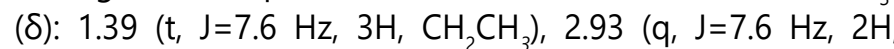
$\left.\mathrm{CH}_{2} \mathrm{CH}_{3}\right), 3.92\left(\mathrm{~s}, 6 \mathrm{H}, \mathrm{OCH}_{3}\right), 7.75\left(\mathrm{~d}, \mathrm{~J}=2.1 \mathrm{~Hz}, 1 \mathrm{H}, \mathrm{C}_{5^{\prime}}-\mathrm{H}\right), 7.87$ (dd, J=8.5, 2.1 Hz, 1H, C $\left.\mathrm{C}_{5}-\mathrm{H}\right), 7.95\left(\mathrm{dd}, \mathrm{J}=8.1,6.3 \mathrm{~Hz}, 2 \mathrm{H}, \mathrm{C}_{2^{\prime \prime}}\right.$ $\left.\mathrm{C}_{6^{\prime}}-\mathrm{H}\right), 8.26\left(\mathrm{dd}, \mathrm{J}=7.4,1.0 \mathrm{~Hz}, 1 \mathrm{H}, \mathrm{C}_{4}-\mathrm{H}\right), 8.86(\mathrm{~d}, \mathrm{~J}=7.8 \mathrm{~Hz}, 2 \mathrm{H}$ $\mathrm{C}_{2^{\prime}} \mathrm{C}_{6}-\mathrm{H}$ ). Anal. Calcd. For $\mathrm{C}_{16} \mathrm{H}_{18} \mathrm{~N}_{2} \mathrm{O}_{3}$ (286.33): $\mathrm{C}, 59.54 ; \mathrm{H}$, 6.06; $N, 6.23$. Found: $C, 59.93 ; H, 5.66 ; N, 8.74$.

$\begin{array}{lll}\text { Synthesis of } \mathrm{N} \text {-(3,5-Trifluoromethylbenzoylimino)-3- } \\ \text { ethylpyridinium } \quad \text { Ylide } & \text { (8c): } & \text { 3-ethylpyridinium }\end{array}$ mesitylenesulfonate (6) $(2.00 \mathrm{~g}, 6.17 \mathrm{mmol})$ in $30 \mathrm{~mL}$ of anhydrous THF at $70^{\circ} \mathrm{C}$ was stirred for fifteen minutes before 3,5-trifluoromethylbenzoyl chloride (7) $(2.24 \mathrm{~mL}, 12.34 \mathrm{mmol})$ was added. The mixture ran overnight. After twenty-four hours, $100 \mathrm{~mL}$ of $\mathrm{NaHCO}_{3}$ arrested the reaction. The product, $\mathrm{N}$-(3,5-Trifluoromethylbenzoylimino)-3-ethylpyridinium ylide (8c) was extracted with $100 \mathrm{~mL}$ of $\mathrm{CH}_{2} \mathrm{Cl}_{2}$ three times and dried over sodium sulfate $\left(\mathrm{Na}_{2} \mathrm{SO}_{4}\right)$. The ylide was obtained by filtration and evaporation of the solvent, then purified by flash column chromatography using ethyl acetate: hexane $(6: 4 \mathrm{v} / \mathrm{v})$. The result $(\mathbf{8 c})$ was a white solid $(2.14 \mathrm{~g}, 95 \%)$; $\mathrm{mp}$ : 202.0-205.4 ${ }^{\circ} \mathrm{C} ;{ }^{1} \mathrm{H}-\mathrm{NMR}\left(300 \mathrm{MHz} \mathrm{CDCl}_{3}\right)(\delta): 1.43(\mathrm{t}, \mathrm{J}=7.6 \mathrm{~Hz}$, $\left.3 \mathrm{H}, \mathrm{CH}_{2} \mathrm{CH}_{3}\right), 2.98\left(\mathrm{q}, \mathrm{J}=7.6 \mathrm{~Hz}, 2 \mathrm{H}, \mathrm{CH}_{2} \mathrm{CH}_{3}\right), 6.74\left(\mathrm{~s}, 2 \mathrm{H}, \mathrm{C}_{2^{\prime \prime}}\right.$ $\left.\mathrm{C}_{6}-\mathrm{H}\right), 8.02\left(\mathrm{dd}, \mathrm{J}=8.0,6.3 \mathrm{~Hz}, 2 \mathrm{H}, \mathrm{C}_{5}-\mathrm{H}\right), 8.32(\mathrm{~d}, \mathrm{~J}=8.4 \mathrm{~Hz}, 1 \mathrm{H}$, $\left.\mathrm{C}_{4^{\prime}}-\mathrm{H}\right), 8.56\left(\mathrm{~s}, 2 \mathrm{H}, \mathrm{C}_{4}-\mathrm{H}\right), 8.88-8.98\left(\mathrm{~m}, 2 \mathrm{H}, \mathrm{C}_{2^{\prime}} \mathrm{C}_{6}-\mathrm{H}\right)$. Anal. Calcd. For $\mathrm{C}_{16} \mathrm{H}_{12} \mathrm{~F}_{6} \mathrm{~N}_{2} \mathrm{O}$ (362.27): $\mathrm{C}, 53.42 ; \mathrm{H}_{1} 4.28 ; \mathrm{N}, 4.93$. Found: $\mathrm{C}, 53.03 ; \mathrm{H}, 3.34 ; \mathrm{N}, 7.73$.

\section{General procedure 2}

Synthesis of N-(3,5-Dimethylbenzoylimino)-3-ethylpyridinium Ylide (8d): Triethylamine $(4.74 \mathrm{~mL})$ was added in one portion to a suspension of $\mathrm{N}$-hydroxyphthalimide (10) $(5.00 \mathrm{~g}, 30.65$ $\mathrm{mmol}$ ) in $100 \mathrm{~mL}$ of acetone. The mixture was stirred at room temperature. When the reaction became a homogeneous solution, 2,4-dinitrochlorobenzene (11) $(6.21 \mathrm{~g}, 30.65 \mathrm{mmol})$ was added and stirred at room temperature for two hours. After the two hours, a bright yellow suspension was formed and poured into $500 \mathrm{~mL}$ of ice water. The precipitate was filtered and washed three times with $100 \mathrm{~mL}$ of cold methanol $(\mathrm{MeOH})$. The solid was compressed and washed three times with $100 \mathrm{~mL}$ of hexane and dried under vacuum to afford 2-(2,4-dinitrophenoxy)-1-H-isoindole-1,3-(2H)-dione $(7.75 \mathrm{~g}, 23.90 \mathrm{mmol})$ as an off white solid.

A solution of hydrazine hydrate $(6.16 \mathrm{~mL}, 135.36 \mathrm{mmol})$ in $30 \mathrm{~mL}$ of $\mathrm{MeOH}$ was added in one portion to a solution of (12) in $200 \mathrm{~mL}$ of $\mathrm{CH}_{2} \mathrm{Cl}_{2}$ at $0^{\circ} \mathrm{C}$. The reaction mixture rapidly 
became bright yellow and the precipitate was formed. The suspension was allowed to stand at $0^{\circ} \mathrm{C}$ for eight hours, $10 \mathrm{~mL}$ of cold aqueous $\mathrm{HCl}(1 \mathrm{~N}, 400 \mathrm{~mL}$ ) was added, and the reaction was shaken rapidly at $0^{\circ} \mathrm{C}$. The mixture was filtered using a Büchner funnel and the precipitate was washed three times with $50 \mathrm{~mL}$ of $\mathrm{MeCN}$. The filtrate was poured into a separatory funnel, and the organic phase was separated. The aqueous phase was extracted twice with $100 \mathrm{~mL}$ of $\mathrm{CH}_{2} \mathrm{Cl}_{2}$. The organic phase was combined, dried over $\mathrm{Na}_{2} \mathrm{SO}_{4^{\prime}}$ filtered, and concentrated by rotoevaporation produced O-(2,4-Dinitrophenyl)hydroxylamine(13) [23].

O-(2,4-Dinitrophenyl)hydroxylamine (13) (4.08 g, 20.53 $\mathrm{mmol}$ ) was added to $30 \mathrm{~mL}$ of MeCN. 3-ethylpyridine (5) (2.10 $\mathrm{mL}, 18.66 \mathrm{mmol}$ ) was added slowly to the reaction mixture. The reaction stirred at $40^{\circ} \mathrm{C}$ for 12 hours. The reaction mixture turned dark red and formed the 3-ethylpyridinium 2,4-dinitrophenolate salt (14). The salt (14) $(1.36 \mathrm{~g}, 4.44 \mathrm{mmol})$ was left to react with 3,5-dimethylbenzoyl chloride (7) $(1.97 \mathrm{~mL}, 13.32 \mathrm{mmol})$ in $30 \mathrm{~mL}$ of THF and $\mathrm{Et}_{3} \mathrm{~N}(0.93 \mathrm{~mL}, 6.66 \mathrm{mmol})$ at $70^{\circ} \mathrm{C}$ overnight. After twenty-four hours, $100 \mathrm{~mL}$ of saturated sodium bicarbonate $\left(\mathrm{NaHCO}_{3}\right)$ arrested the reaction. The product, $\mathrm{N}-(3,5-$ dimethylbenzoylimino)-3-ethylpyridinium ylide (8d) was extracted with $100 \mathrm{~mL}$ of $\mathrm{CH}_{2} \mathrm{Cl}_{2}$ three times and dried over sodium sulfate $\left(\mathrm{Na}_{2} \mathrm{SO}_{4}\right)$. The ylide was obtained by filtration and evaporation of the solvent, then purified by flash column chromatography using ethyl acetate: hexane (6:4 v/v). General Procedure 2 scheme is shown in figure 2 . The result (8d) was a white solid (0.25 g, 22\%); mp: $223.0-226.0^{\circ} \mathrm{C} ;{ }^{1} \mathrm{H}-\mathrm{NMR}(300 \mathrm{MHz}$ $\left.\mathrm{CDCl}_{3}\right)(\delta): 1.36\left(\mathrm{t}, \mathrm{J}=7.6 \mathrm{~Hz}, 3 \mathrm{H}, \mathrm{CH}_{2} \mathrm{CH}_{3}\right), 2.36\left(\mathrm{~s}, 6 \mathrm{H}, \mathrm{CH}_{3}\right), 2.91(\mathrm{q}$, $\left.\mathrm{J}=7.8 \mathrm{~Hz}, 2 \mathrm{H}, \mathrm{CH}_{2} \mathrm{CH}_{3}\right), 7.91\left(\mathrm{~s}, 2 \mathrm{H}, \mathrm{C}_{2^{\prime \prime}} \mathrm{C}_{6^{\prime}}-\mathrm{H}\right), 7.98(\mathrm{dd}, \mathrm{J}=8.0,6.3$ $\left.\mathrm{Hz}, 1 \mathrm{H}, \mathrm{C}_{4^{\prime}}-\mathrm{H}\right), 8.29\left(\mathrm{~d}, \mathrm{~J}=7.8 \mathrm{~Hz}, 1 \mathrm{H}, \mathrm{C}_{5}-\mathrm{H}\right), 8.79\left(\mathrm{~s}, 1 \mathrm{H}, \mathrm{C}_{4}-\mathrm{H}\right), 8.83$ (d, J=6.3 Hz, 2H, C $2_{2} \mathrm{C}_{6}-\mathrm{H}$ ). Anal. Calcd. For $\mathrm{C}_{16} \mathrm{H}_{18} \mathrm{~N}_{2} \mathrm{O}$ (254.33): C, 65.17; H, 6.40; N, 9.36. Found: C, 65.37; H, 6.17; N, 9.53.

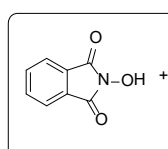

10

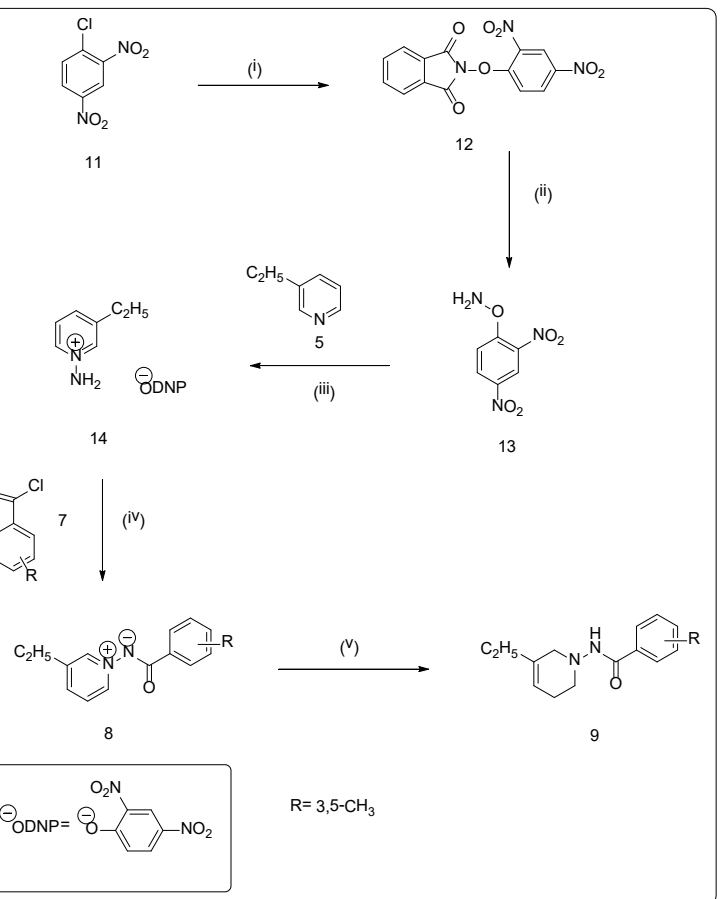

Figure 2. Scheme 2 reactions and conditions: (i) $\mathrm{Et}_{3} \mathrm{~N}_{\text {, }}$ 2,4-dinitrochlorobenzene, Acetone, $\mathrm{RT}, 2 \mathrm{~h}$ (ii) $\mathrm{NH}_{2} \mathrm{NH}_{2} \cdot \mathrm{H}_{2} \mathrm{O}$, DCM: $\mathrm{MeOH}, 0^{\circ} \mathrm{C}, 8 \mathrm{~h}$ (iii) 3-ethylpyridine (5), $\mathrm{MeCN}, 40^{\circ} \mathrm{C}, 12 \mathrm{~h}$ (iv)

a.) Substituted acyl chloride (7), $\mathrm{THF}_{1} \mathrm{Et}_{3} \mathrm{~N}, 70^{\circ} \mathrm{C}$, overnight b.) $\mathrm{NaHCO}_{3} / \mathrm{H}_{2} \mathrm{O}(\mathrm{v}) \mathrm{NaBH}_{4^{\prime}}$ abs. EtOH, $0^{\circ} \mathrm{C}, 7 \mathrm{~h}$.

\section{General procedure 3}

Synthesis of N-(1-Naphthoylamino)-5-ethyl-1,2,3,6tetrahydropyridines (9a): Sodium borohydride $(0.14 \mathrm{~g}, 3.60$ $\mathrm{mmol})$ was added to a solution of $(8 \mathbf{a})(0.20 \mathrm{~g}, 0.72 \mathrm{mmol})$ in $13 \mathrm{~mL}$ of absolute ethanol at $0^{\circ} \mathrm{C}$. The reaction stirred for seven hours and was monitored by TLC. The reaction was arrested with ice and allowed to warm to room temperature. Compound (9a) was extracted with dichloromethane $(3 \times 100$ $\mathrm{mL})$. The combined extracts were dried over sodium sulfate $\left(\mathrm{Na}_{2} \mathrm{SO}_{4}\right)$, filtered, and rotoevaporated. The solid obtained was purified by flash column chromatography using ethyl acetate: hexane $(6: 4 \mathrm{v} / \mathrm{v})$. Rotoevaporation gave an off white solid (0.02 g, 10\%); mp: 194.7- $197.5^{\circ} \mathrm{C} ; \mathrm{IR}$ (potassium bromide): v $3161(\mathrm{NH}), 1661$ (CO) cm ${ }^{-1} ;{ }^{1} \mathrm{H}-\mathrm{NMR}(300 \mathrm{MHz}$ $\left.\mathrm{CDCl}_{3}\right)(\delta): 1.03\left(\mathrm{t}, \mathrm{J}=7.5 \mathrm{~Hz}, 3 \mathrm{H}, \mathrm{CH}_{2} \mathrm{CH}_{3}\right), 1.98-2.04(\mathrm{q}, \mathrm{J}=3,7.8$ $\left.\mathrm{Hz}, 2 \mathrm{H}, \mathrm{CH}_{2} \mathrm{CH}_{3}\right), 2.35\left(\mathrm{~s}, 2 \mathrm{H}, \mathrm{C}_{5}-\mathrm{H}\right), 3.13\left(\mathrm{t}, \mathrm{J}=5.9 \mathrm{~Hz}, 2 \mathrm{H}, \mathrm{C}_{2^{\prime}}\right.$ $\left.\mathrm{C}_{6}-\mathrm{H}\right), 5.52\left(\mathrm{~s}, 1 \mathrm{H}, \mathrm{C}_{4}-\mathrm{H}\right), 7.26-7.59\left(\mathrm{~m}, 2 \mathrm{H}, \mathrm{C}_{5^{\prime \prime}} \mathrm{C}_{9^{\prime}}-\mathrm{H}\right), 7.80(\mathrm{~d}$, $\left.\mathrm{J}=8.3 \mathrm{~Hz}, 1 \mathrm{H}, \mathrm{C}_{4^{\prime}}-\mathrm{H}\right), 7.90\left(\mathrm{dd}, \mathrm{J}=15.5,8.0 \mathrm{~Hz}, 3 \mathrm{H}, \mathrm{C}_{6^{\prime \prime}} \mathrm{C}_{8^{\prime \prime}} \mathrm{C}_{9^{\prime}}-\mathrm{H}\right)$, $8.27\left(\mathrm{~s}, 1 \mathrm{H}, \mathrm{C}_{3}-\mathrm{H}\right), 7.01\left(\mathrm{br}, \mathrm{s}, \mathrm{NH}, \mathrm{D}_{2} \mathrm{O}\right.$ Exchange); ${ }^{13} \mathrm{C}-\mathrm{NMR}$ $\left(600 \mathrm{MHz} \mathrm{CDCl}_{3}\right)(\delta): 11.8\left(\mathrm{CH}_{2} \mathrm{CH}_{3}\right), 23.2\left(\mathrm{C}_{5}\right), 27.3\left(\mathrm{CH}_{2} \mathrm{CH}_{3}\right)$, $53.4\left(C_{6}\right), 56.4\left(C_{2}\right), 117.5\left(C_{4}\right), 123\left(C_{9}\right), 127\left(C_{7}\right), 128\left(C_{3}\right), 129$ $\left(C_{2^{\prime}}\right), 130\left(C_{10}\right), 132\left(C_{5^{\prime}}\right), 133\left(C_{4^{\prime}}\right), 134\left(C_{8}\right), 136\left(C_{3}\right), 164(C=0)$. Anal. Calcd. For $\mathrm{C}_{18} \mathrm{H}_{20} \mathrm{~N}_{2} \mathrm{O}$ (280.36): C, 76.69; $\mathrm{H}, 7.25 ; \mathrm{N}, 9.67$. Found: C, 76.39; H, 7.12; N, 9.90.

Synthesis of N-(3,4-Dimethoxybenzoylamino)-5-ethyl1,2,3,6-tetrahydropyridines (9b): Sodium borohydride $(0.13 \mathrm{~g}, 3.50 \mathrm{mmol})$ was added to a solution of $(\mathbf{8 b})(0.20 \mathrm{~g}$, $0.70 \mathrm{mmol}$ ) in $13 \mathrm{~mL}$ of absolute ethanol at $0^{\circ} \mathrm{C}$. The reaction was worked up as outlined in general procedure 3. Compound (9b) was extracted with dichloromethane $(3 \times 100 \mathrm{~mL})$. The combined extracts were dried over $\mathrm{Na}_{2} \mathrm{SO}_{4^{\prime}}$ filtered, and rotoevaporated. The solid obtained was purified by flash column chromatography using ethyl acetate: hexane (6:4 v/v). Rotoevaporation gave a white solid $(0.20 \mathrm{~g}, 20 \%) ; \mathrm{mp}: 132.2-$ $134.3^{\circ} \mathrm{C}$; IR (potassium bromide): $03292(\mathrm{NH}), 1640(\mathrm{CO}) \mathrm{cm}^{-1}$; ${ }^{1} \mathrm{H}-\mathrm{NMR}\left(300 \mathrm{MHz} C D C l_{3}\right)(\delta): 1.02\left(\mathrm{t}, \mathrm{J}=7.8 \mathrm{~Hz}, 3 \mathrm{H} \mathrm{CH}_{2} \mathrm{CH}_{3}\right)$, 1.93-2.0 (q, J=6.9, 7.8 Hz, 2H, $\left.\mathrm{CH}_{2} \mathrm{CH}_{3}\right), 3.08(\mathrm{t}, \mathrm{J}=5.7 \mathrm{~Hz}, 2 \mathrm{H}$, $\left.\mathrm{C}_{6}-\mathrm{H}\right), 3.42\left(\mathrm{~s}, 2 \mathrm{H}, \mathrm{C}_{2}-\mathrm{H}\right) ; 3.92\left(\mathrm{~s}, 6 \mathrm{H}_{1}-\mathrm{OCH}_{3}\right), 5.49\left(\mathrm{~s}, 1 \mathrm{H}, \mathrm{C}_{4}-\mathrm{H}\right)$ $7.23\left(\mathrm{t}, \mathrm{J}=7.2 \mathrm{~Hz}, 1 \mathrm{H}, \mathrm{C}_{5}-\mathrm{H}\right), 7.51-7.54(\mathrm{q}, \mathrm{J}=3.0,2.7 \mathrm{~Hz}, 1 \mathrm{H}$ $\left.\mathrm{C}_{6}-\mathrm{H}\right), 7.69-7.72\left(\mathrm{q}, \mathrm{J}=3.0 \mathrm{~Hz}, 1 \mathrm{H}, \mathrm{C}_{2}-\mathrm{H}\right), 7.01\left(\mathrm{br}, \mathrm{s}, \mathrm{NH}, \mathrm{D}_{2} \mathrm{O}\right.$ Exchange); ${ }^{13} \mathrm{C}-\mathrm{NMR}\left(600 \mathrm{MHz} \mathrm{CDCl}_{3}\right)(\delta): 11.8\left(\mathrm{CH}_{2} \mathrm{CH}_{3}\right), 23.2$ $\left(\mathrm{C}_{4}\right), 27.3\left(\mathrm{CH}_{2} \mathrm{CH}_{3}\right), 56.0\left(\mathrm{OCH}_{3}\right), 60.3\left(\mathrm{C}_{3}\right), 61.4\left(\mathrm{C}_{2}\right), 111\left(\mathrm{C}_{5}\right)$, $112\left(C_{2}\right), 117.5\left(C_{4}\right), 120.8\left(C_{6}\right), 127.5\left(C_{1}\right), 136.4\left(C_{3}\right), 149\left(C_{3}\right)$, $153\left(C_{4}\right), 165(C=0)$. Anal. Calcd. For $\mathrm{C}_{16} \mathrm{H}_{22} \mathrm{~N}_{2} \mathrm{O}_{3}$ (290.36): $\mathrm{C}_{1}$ $66.18 ; H, 7.64 ; \mathrm{N}, 9.65$. Found: $C, 65.97 ; H, 7.57 ; \mathrm{N}, 9.58$.

\section{Synthesis of $\mathrm{N}$-(3,5-Trifluoromethylbenzoylamino)-5- ethyl-1,2,3,6-tetrahydropyridines (9c): Sodium} borohydride $(0.16 \mathrm{~g}, 4.15 \mathrm{mmol})$ was added to a solution of (8c) $(0.300 \mathrm{~g}, 0.83 \mathrm{mmol})$ in $20 \mathrm{~mL}$ of absolute ethanol at $0^{\circ} \mathrm{C}$. The reaction was worked up as outlined in general procedure 3. Compound (9c) was extracted with dichloromethane $(3 \times$ $100 \mathrm{~mL}$ ). The combined extracts were dried over $\mathrm{Na}_{2} \mathrm{SO}_{4^{\prime}}$ filtered, and rotoevaporated. The solid obtained was purified by flash column chromatography using ethyl acetate: hexane $(6: 4 \mathrm{v} / \mathrm{v})$. Rotoevaporation gave a white solid $(0.11 \mathrm{~g}, 36 \%)$

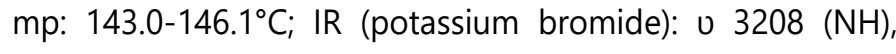


$1690(\mathrm{CO}) \mathrm{cm}^{-1} ;{ }^{1} \mathrm{H}-\mathrm{NMR}\left(300 \mathrm{MHz} \mathrm{CDCl}_{3}\right)(\delta): 1.03(\mathrm{t}, \mathrm{J}=7.4$ $\left.\mathrm{Hz}, 3 \mathrm{H}, \mathrm{CH}_{2} \mathrm{CH}_{3}\right), 1.98\left(\mathrm{q}, \mathrm{J}=8.1 \mathrm{~Hz}, 2 \mathrm{H}, \mathrm{CH}_{2} \mathrm{CH}_{3}\right), 3.10\left(\mathrm{~s}, 2 \mathrm{H}, \mathrm{C}_{3^{\prime \prime}}\right.$ $\left.\mathrm{C}_{5},-\mathrm{H}\right), 3.44\left(\mathrm{~s}, 2 \mathrm{H}, \mathrm{C}_{2}, \mathrm{C}_{6}-\mathrm{H}\right), 5.48\left(\mathrm{~d}, \mathrm{~J}=18.0 \mathrm{~Hz}, 1 \mathrm{H}, \mathrm{C}_{4}-\mathrm{H}\right), 8.19$ $\left(\mathrm{s}, 2 \mathrm{H}, \mathrm{C}_{2^{\prime \prime}}, \mathrm{C}_{6^{\prime}}-\mathrm{H}\right), 8.34\left(\mathrm{~s}, 1 \mathrm{H}, \mathrm{C}_{4^{\prime}}-\mathrm{H}\right), 7.12\left(\mathrm{br}, \mathrm{s}, \mathrm{NH}, \mathrm{D}_{2} \mathrm{O}\right.$ Exchange); ${ }^{13} \mathrm{C}-\mathrm{NMR}\left(600 \mathrm{MHz} \mathrm{CDCl}_{3}\right)(\delta): 11.68\left(\mathrm{CH}_{2} \mathrm{CH}_{3}\right)$, $23.76\left(\mathrm{C}_{5}\right), 27.31\left(\mathrm{CH}_{2} \mathrm{CH}_{3}\right), 52.25\left(\mathrm{C}_{6}\right), 56.27\left(\mathrm{C}_{2}\right), 117.31\left(\mathrm{C}_{4}\right)$, $125.74\left(C_{4^{\prime}}\right), 123.72\left(C_{3}\right), 128.20\left(C_{2^{\prime \prime}} C_{6^{\prime}}\right), 132.11\left(C_{3^{\prime \prime}} C_{5^{\prime}}\right)$, $132.33\left(C_{1}\right), 134.47\left(C_{3}\right), 163.47(C=0)$. Anal. Calcd. For $\mathrm{C}_{16} \mathrm{H}_{16} \mathrm{~F}_{6} \mathrm{~N}_{2} \mathrm{O}$ (366.30): C, 52.46; $\mathrm{H}, 4.40 ; \mathrm{N}, 7.65$. Found: $\mathrm{C}_{\text {, }}$ 52.70; H, 4.40; N, 7.59.

Synthesis of N-(3,5-Dimethylbenzoylamino)-5-ethyl1,2,3,6-tetrahydropyridines (9d): Sodium borohydride $(0.19 \mathrm{~g}, 4.90 \mathrm{mmol})$ was added to a solution of $(\mathbf{8 d})(0.25 \mathrm{~g}$, $0.98 \mathrm{mmol}$ ) in $30 \mathrm{~mL}$ of absolute ethanol at $0^{\circ} \mathrm{C}$. The reaction was worked up as outlined in general procedure 3. Compound (9d) was extracted with dichloromethane $(3 \times 100 \mathrm{~mL})$. The combined extracts were dried over $\mathrm{Na}_{2} \mathrm{SO}_{4^{\prime}}$ filtered, and rotoevaporated. The solid obtained was purified by flash column chromatography using ethyl acetate: hexane $(6: 4 \mathrm{v} / \mathrm{v})$. Rotoevaporation gave a white solid $(0.11 \mathrm{~g}, 44 \%)$; $\mathrm{mp}: 155.4-$ $157.8^{\circ} \mathrm{C}$; IR (potassium bromide): ט $3232(\mathrm{NH}), 1632(\mathrm{CO}) \mathrm{cm}^{-1}$;

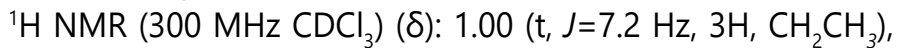
$1.95\left(\mathrm{~d}, J=6.7 \mathrm{~Hz}, 2 \mathrm{H}, \mathrm{CH}_{2} \mathrm{CH}_{3}\right), 2.32\left(\mathrm{~s}, 6 \mathrm{H}, \mathrm{CH}_{3}\right), 3.17(\mathrm{~s}, 2 \mathrm{H}$, $\left.\mathrm{C}_{2}-\mathrm{H}\right), 5.48\left(\mathrm{~s}, 1 \mathrm{H}, \mathrm{C}_{4}-\mathrm{H}\right), 7.36\left(\mathrm{~s}, 2 \mathrm{H}, \mathrm{C}_{2^{\prime \prime}} \mathrm{C}_{6^{\prime}}-\mathrm{H}\right), 7.11\left(\mathrm{~s}, \mathrm{NH}, \mathrm{D}_{2} \mathrm{O}\right.$ Exchange); ${ }^{13} \mathrm{C}-\mathrm{NMR}\left(600 \mathrm{MHz} \mathrm{CDCl}_{3}\right)(\delta): 11.77\left(\mathrm{CH}_{2} \mathrm{CH}_{3}\right)$, $21.16\left(\mathrm{CH}_{3}\right), 23.89\left(\mathrm{C}_{5}\right), 27.40\left(\mathrm{CH}_{2} \mathrm{CH}_{3}\right), 52.18\left(\mathrm{C}_{6}\right), 56.36\left(\mathrm{C}_{2}\right)$, $117.5\left(C_{4}\right), 126.67\left(C_{2^{\prime \prime}} C_{6}\right), 132.00\left(C_{1}\right), 134.07\left(C_{1}\right), 135.05\left(C_{3}\right)$, 138. $51\left(\mathrm{C}_{3}\right), 166.13(\mathrm{C}=\mathrm{O})$. Anal. Calcd. For $\mathrm{C}_{16} \mathrm{H}_{22} \mathrm{~N}_{2} \mathrm{O}$ (258.36): C, 74.38; H, 8.58; N, 10.84. Found: C, 74.63; H, 8.65; N 10.76.

\section{Antiproliferative activity studies}

Human MCF-7 and MDA-MB-231 breast cancer cell lines were purchased from the $\mathrm{NCl}$. The human Ishikawa endometrial cancer cell line was purchased from Sigma Aldrich. All three cell lines were cultured in phenol red-free RPMI-1640 (Hyclone) (500 mL) supplemented with L-glutamine-dipeptide (Hyclone) $(5 \mathrm{~mL})$, and $10 \%$ fetal bovine serum (Atlanta Biologicals) $(50 \mathrm{~mL})$.

They were maintained in exponential growth phase by sub-culturing twice weekly in $150-\mathrm{cm}^{2}$ flasks at $37^{\circ} \mathrm{C}, 95 \%$ air with $5 \% \mathrm{CO}_{2}$. The media was removed from the flasks, the cells were washed with phosphate buffer solution (PBS) (HyClone) and then detached using $5 \mathrm{~mL}$ of TryplExpress solution (Invitrogen) (incubation 5-10 min) followed by addition of growth media. Cells were centrifuged (1,500 rpm) for 5 minutes and re-suspended in growth media at $10^{5}$ cells/ $\mathrm{mL}$. The cell lines were placed in 20,96 well plates at a density of 5000 cells/well in total volume of $50 \mu \mathrm{L}$ in phenol-red free medium and incubated overnight. Compounds were weighed and dissolved in DMSO $(10 \mu \mathrm{M})$ and tested at different concentrations ranging from 0.01 to $100,000 \mathrm{nM}$. Tamoxifen (TAM, $10 \mu \mathrm{M})$ and 4-hydroxytamoxifen (4-OHT, $10 \mu \mathrm{M})$ were used as positive controls. Estradiol ( $25 \mu \mathrm{L}$ of $40 \mathrm{nM}$ ) was added to all appropriate wells in the plate. $25 \mu \mathrm{L}$ media was added to all wells that did not receive estradiol. $25 \mu \mathrm{L}$ of stocks (contain compounds, DMSO and phenol-red free medium) were added to cells and medium already on plate. $50 \mu \mathrm{L}$ media was added to media wells, $50 \mu \mathrm{L}$ mix (contain 32 $\mathrm{mL} \mathrm{DMSO}+768 \mathrm{~mL}$ phenol-red free medium) was added to all vehicle control wells and $10 \mu \mathrm{M}$ TAM and $10 \mu \mathrm{M} 4-\mathrm{OHT}$ were also added to appropriate wells. Drug exposed cells were incubated for 72 hours, after which the plates were removed for CellTiter-Glo assay (Promega) from $37^{\circ} \mathrm{C}, 5 \% \mathrm{CO}_{2}$ incubator and equilibrated at room temperature for 30 minutes.

$100 \mu \mathrm{L}$ of CellTiter-Glo assay reagent was added to each well and cell lysis was induced on an orbital shaker for 2 minutes followed by further 10 minutes incubation at room temperature. Luminescence results were read on TriLux Luminometer. The luminescent signal was proportional to the number of active cells present in culture. Dead cells do not affect cell counts because they do not contribute to ATP content. As a consequence, the number of metabolically active cells can be directly derived from the luminescent signal using a specific calibration curve. The results expressed as $I_{50}$ (inhibitory concentration of $50 \%$ ) were the averages of three data points for each concentration and were calculated using GraphPad Prism 4.0.

\section{Molecular modeling}

All computational studies were performed using SYBYL-X 2.1 and OpenEye Scientific software packages based on a Windows XP workstation [20]. The structures used in this manuscript were drawn using Sybyl sketch and energy minimized using MMFF94 force field and MMFF94 charges (method: Conjugate Gradient, termination: gradient $0.05 \mathrm{kcl} / \mathrm{mol}^{\circ}$, and max. iterations: 100,000) as implemented in SYBYL. OpenEye Scientific Software's OEDOCKING-HYBRID was the computer software used to dock the THPs to the ER $\alpha$.

\section{Results}

Four substituted tetrahydropyridines (Figure 3) have been synthesized, characterized, and their antiproliferative activity determined using Ishikawa, MCF-7, and MDA-MB-231 cell lines. The goal was to evaluate the effect of a few substitutions on the benzoyl ring of the THPs towards anti-cancer activity. In this regard, high-quality biological testing results were determined for the newly synthesized compounds along with Tamoxifen and 4-Hydrotamoxifen (Table 1).

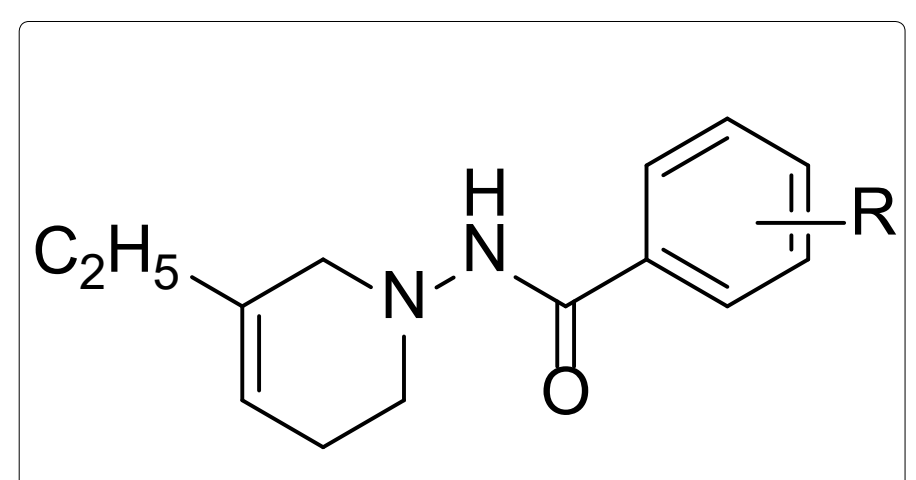

Figure 3. General structure of the tetrahydropyridines. $\mathrm{R}=3,4-\mathrm{OCH}_{3^{\prime}}$ $\mathrm{C}_{4} \mathrm{H}_{4^{\prime}} 3,5-\mathrm{CF}_{3}, 3,5-\mathrm{CH}_{3}$ 
Table 1. Antiproliferative Activity of Tetrahydropyridines: The antiproliferative activity studies of four tetrahydropyridines,

Tamoxifen, and 4-Hydroxytamoxifen against Ishikawa, MCF-7, and MDA-MB-231 cell lines.

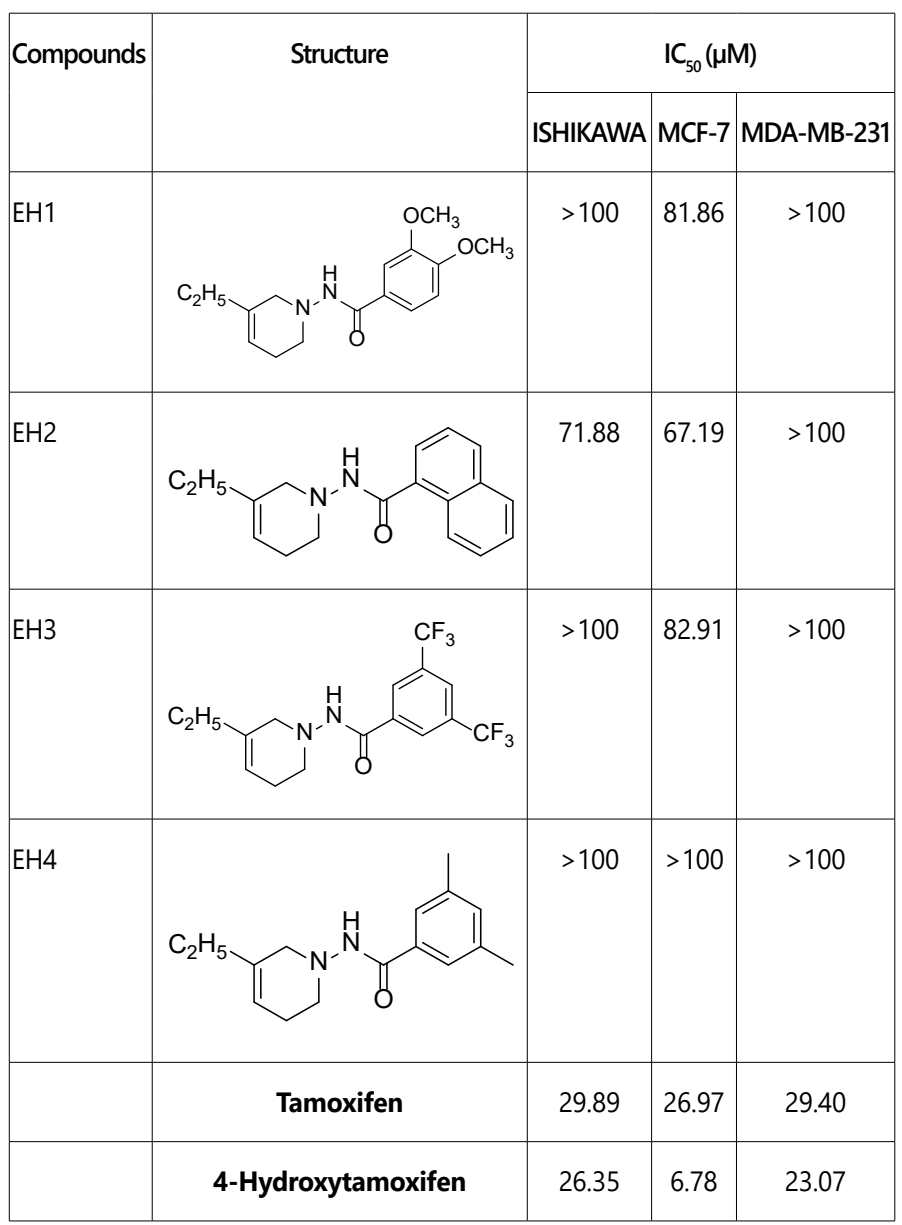

Molecular modeling was used to provide an illustration of the three-dimension spatial arrangement of chemical features that are essential for biological activity. Figures 4-7 show the docking of THP derivatives to the ER $\alpha$. Each figure contains the best conformation of the THPs to the active site of ER $\alpha$. The docking scores for the THPs are shown in table 2. A docking score is used to predict the binding affinity between the THPs and ER $\alpha$. The docking scores were calculated based on four parameters: shape, hydrogen bonding, protein desolvation, and ligand desolvation. The higher the absolute value is for the docking score the better the binding affinity is to the $E R \alpha$.

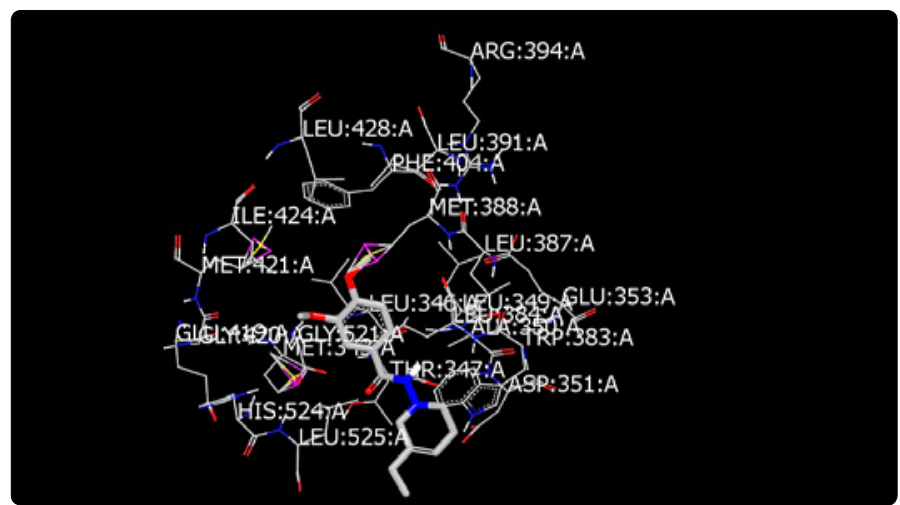

Figure 4. Docking of $E H 1$ to $E R \alpha$ : $E H 1$ has a slight affinity for amino acids in the active site.

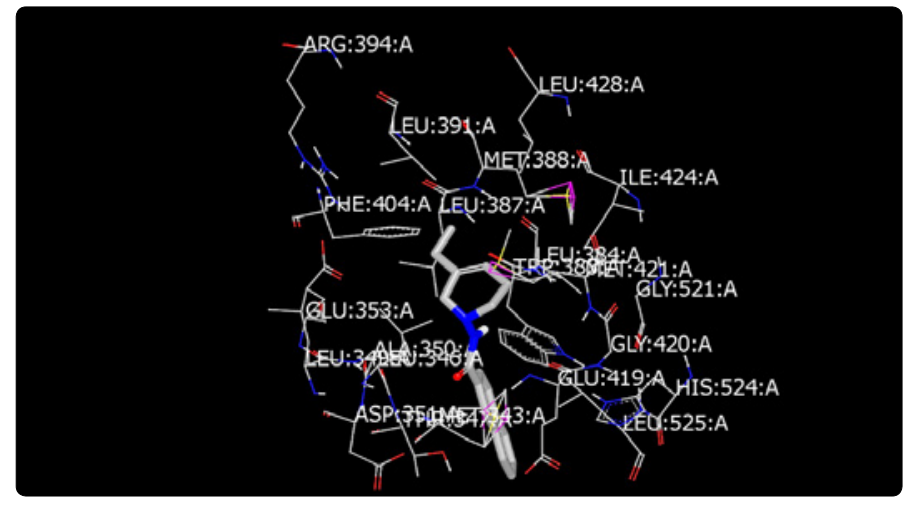

Figure 5. Docking of $\mathrm{EH} 2$ to $\mathrm{ER} \alpha$ : $\mathrm{EH} 2$ showed pi stacking interactions with the amino acids within the active site.

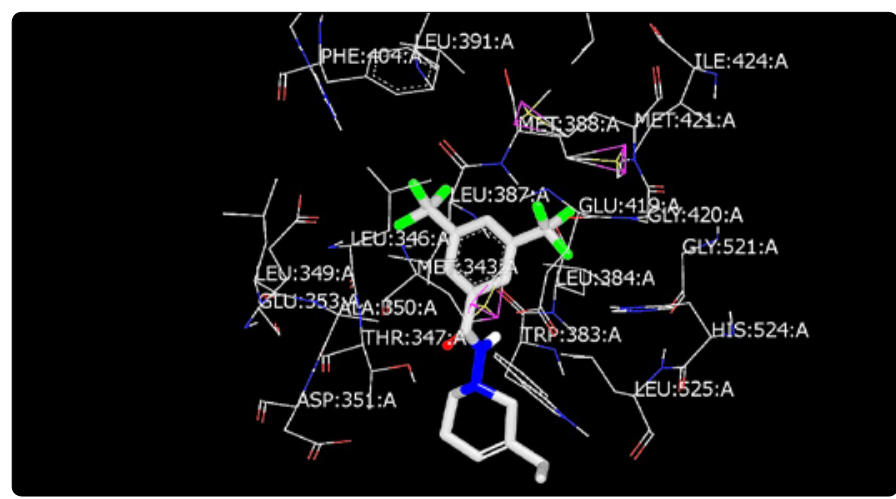

Figure 6. Docking of $\mathrm{EH} 3$ to $\mathrm{ER} \alpha \mathrm{EH} 3$ has a slight affinity for amino acids in the active site.

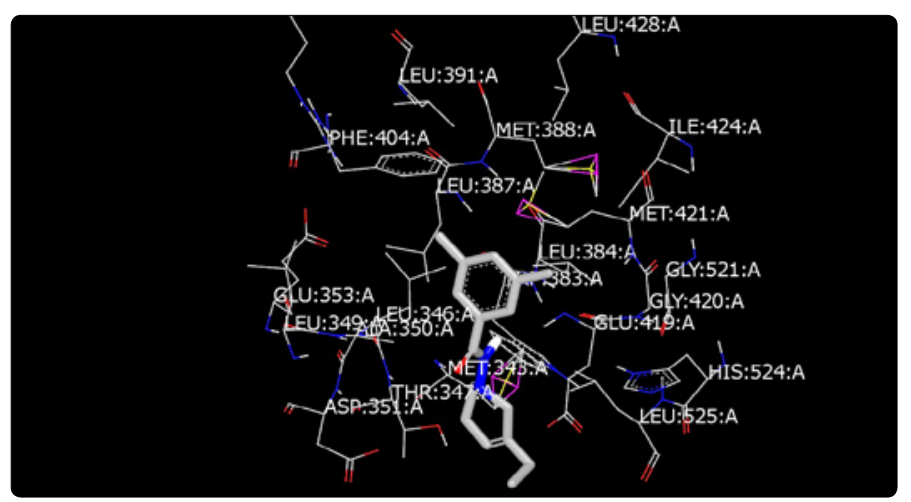

Figure 7. Docking of EH4 to ER $\alpha$ : $\mathrm{EH} 4$ has a slight affinity for amino acids in the active site.

Table 2. Docking Scores of THPs of ER $\alpha$ : The HYBRID Chemgauss4 docking scores of the four tetrahydropyridines, Tamoxifen, and 4-Hydroxytamoxifen were calculated based on four parameters. Out of the four tetrahydropyridines, EH3 had the highest docking score for ER $\alpha$.

\begin{tabular}{|l|l|}
\hline Compounds & HYBRID Chemgauss4 DOCKING SCORES \\
\hline EH1 & -10.51 \\
\hline EH2 & -10.99 \\
\hline EH3 & -13.59 \\
\hline EH4 & -11.02 \\
\hline Tamoxifen & -20.03 \\
\hline 4-Hydroxytamoxifen & -18.38 \\
\hline
\end{tabular}

\section{Discussion}

Four novel N-Substituted [Benzoylamino]-5-ethyl1,2,3,6-tetrahydropyridine analogs were synthesized. The antiproliferative activity of the tetrahydropyridines were conducted by Southern Research Institute. Table 1 provides 
the antiproliferative activities of the THPs on Ishikawa, MCF7, and MDA-MB-231 cell lines. The $\mathrm{IC}_{50}$ values for Ishikawa ranged from 71.88 to greater than $100 \mu \mathrm{M}$ for the four tetrahydropyridine derivatives. $\mathrm{EH} 2$ had the best $\mathrm{IC}_{50}$ value at $71.88 \mu \mathrm{M}$. $\mathrm{EH} 1, \mathrm{EH} 3$, and $\mathrm{EH} 4$ had $\mathrm{IC}_{50}$ values of greater than $100 \mu \mathrm{M}$. The IC $\mathrm{C}_{50}$ values for MCF-7 ranged from 67.19 to greater than $100 \mu \mathrm{M}$ for the four tetrahydropyridine derivatives. $\mathrm{EH} 2$ had the best $\mathrm{IC} \mathrm{C}_{50}$ value at $67.19 \mu \mathrm{M}$. $\mathrm{EH} 1$ and EH3 had IC $C_{50}$ values of $81.86 \mu \mathrm{M}$ and $82.91 \mu \mathrm{M}$ respectively. $\mathrm{EH} 4$ had an $\mathrm{IC}_{50}$ value of greater than $100 \mu \mathrm{M}$. The $I C_{50}$ values for MDA-MB-231 was greater than $100 \mu \mathrm{M}$ for all the tetrahydropyridine derivatives. The $\mathrm{IC}_{50}$ values for Tamoxifen and 4-Hydroxytamoxifen were $29.89 \mu \mathrm{M}$ and $26.35 \mu \mathrm{M}$ respectively. Although the $\mathrm{IC}_{50}$ values for the THPs were not as good as Tamoxifen and 4-Hydroxytamoxifen, the THP derivatives showed some antiproliferative activity.

OpenEye Scientific Software's OEDOCKING-HYBRID was the computational software used to determine the conformation of the THPs when docked to the active site of $E R \alpha$. The crystal structure of human ER $\alpha$ (PDB ID: 1X7E) showed that glutamic acid 353 (Glu353), arginine 394 (Arg394), glycine 521 (Gly521), and histidine 524 (His524) are the amino acid residues that play key role in stabilizing ligands embedded in the ER cavity [24]. Figures 4-7 show the docking of THP derivatives to the ER $\alpha$. Each figure contains the best conformation of the THPs to the active site of ER $\alpha$. Figures 4, 5 , and 7 showed some hydrogen bonding and van der Waals forces. Compounds EH1, EH3, and EH4 showed a slight interaction between the amino acids that are responsible for stabilizing the ligand within the active site of ER $\alpha$. Figure 5 had the most favorable conformation to the active site of ER $\alpha$. Compound $\mathrm{EH} 2$ showed pi stacking interactions with the amino acids based on the two benzene rings on the compound. Tamoxifen's docking score was -20.03. EH3's docking score was -13.59 . Out of the four THP derivatives, $\mathrm{EH} 3$ had the highest docking score. EH1's HYBRID Chemgauss4 docking score [20] was -10.51. Out of the four THP derivatives, $\mathrm{EH} 1$ had the lowest docking score. EH2 and EH4's docking scores were -10.99 and -11.02 respectively. Based on modeling, EH3 was predicted to have the best antiproliferative activity due to having the highest docking score for ER $\alpha$.

\section{Conclusion}

Four novel N-Substituted [Benzoylamino]-5-ethyl-1,2,3,6tetrahydropyridine analogs were synthesized. The antiproliferative studies for these novel tetrahydropyridines on Ishikawa, MCF-7, and MDA-MB-231 cell lines were done. EH2 had the lowest $I_{50}$ values for Ishikawa and MCF-7 cell lines. EH3 had the highest docking score for the ER $\alpha$. Based on the biological results, the docking studies did not confirm that EH3 would have the best activity. Since the THP exhibited moderate anti-cancer activities, these studies can serve as a template for synthesizing and evaluating more compounds with different structural modifications to improve the biological activities of the compounds by improving the binding affinity to $E R \alpha$.

\section{Conflict of Interest}

Authors declare they have no conflict of interest.

\section{Acknowledgements}

We are grateful to the National Institute of Minority Health and Health Disparities of the National Institute of Health through Grant Number 8 G 12 MD 007582-28 and 2 G12 RR003020 and Center of Excellence in Cancer Research (P20) Grant. We are also grateful to Southern Research Institute, Birmingham, AL, for testing cytotoxicity on Ishikawa, MCF-7, and MDA-MB-231 cell lines and OpenEye Scientific Software, Inc., Santa Fe, NM for free Academic License.

\section{References}

1. American Cancer Society. Cancer Facts \& Figures 2018. 2018.

2. Breastcancer.org. How to Read Hormone Receptor Test Results. 2017.

3. Farzaneh S, Zarghi A. Estrogen Receptor Ligands: A Review (2013-2015). Sci Pharm. 2016; 84(3): 409-427. doi:10.3390/scipharm84030409

4. Maximov PY, Lee TM, Jordan VC. The Discovery and Development of Selective Estrogen Receptor Modulators (SERMs) for Clinical Practice. Curr Clin Pharmacol. 2013; 8(2): 135-155. doi:10.2174/1574884711308020006

5. Redda K, Corleto LA, Knaus EE. Syntheses of N-substituted 2(3,4)pyridylcarboxylic acid hydrazides with analgesic and anti-inflammatory activity. J Med Chem. 1979; 22(9): 1079-1082. doi: 10.1021/jm00195a013

6. Yeung JM, Corleto LA, Knaus EE. Synthesis of N-(carbonylamino)-1,2,3,6tetrahydropyridines with analgesic, anti-inflammatory, and hyperglycemic activity. J Med Chem. 1982; 25(2): 191-195. doi:10.1021/jm00344a020

7. Yeung JM, Corleto LA, Knaus EE. Synthesis of $\mathrm{N}$-[[(substituted-phenyl) carbonyl] amino]-1,2,3,6-tetrahydropyridines with analgesic and hyperglycemic activity. J Med Chem. 1982; 25(6): 720-723. doi: 10.1021/jm00348a021.

8. Redda KK, Melles H, Rao KN. Synthesis of Some N-[Pyridyl(phenyl) carbonylamino]-alkyl-1,2,3,6-tetrahydropyridines. I Heterocycl Chem. 1990; 27(4): 1041-1046. doi:10.1002/jhet.5570270443

9. Pelle CJ, Okoro CO, Wilson TL, Onubogu UC, Yoon KJ, Redda KK. The synthesis of several $\mathrm{N}$-(substituted phenylcarbonylamino)-4-(3-cyclohexenyl)-1,2,3,6tetrahydropyridines as potential anti-inflammatory agents. Synth Commun. 1996; 26(14): 2703-2714. doi: 10.1080/00397919608004587.

10. Wilson T, Redda K. Synthesis and Anti-Inflammatory activity determinations of $\mathrm{N}$-[substituted benzoyl(phenylsulfonyl)amino]-5-ethyl1,2,3,6-tetrahydropyridines. Med Chem Res. 2003; 12(2): 69-86.

11. Redda K, Kode R, Heiman A, Onayemi F, Clark J. Synthesis and AntiInflammatory Activities of Some N-[Pyridyl(phenyl)carbonylamino]-[tertbutyl/phenyl-1,2,3,6-tetrahydropyridines. Chem Pharm Bull (Tokyo). 1991; 39(3): 786-791. doi: 10.1248/cpb.39.786

12. Wilson $T$, Onubogu U, Kode R, Redda K. The Pharmacological Evaluations of Some N-[Pyridyl(Phenyl)Carbonylamino]Hydroxypropyl-1,2,3,6Tetrahydropyridines as Potential Anti-Inflammatory Agents. Drugs Exp Clin Res. 1998; 24(4): 165-172.

13. Okoro C, Yoon K, Wilson T, Onubogu U, Eckford T, Redda K. Synthesis and Biological Evaluations of $\mathrm{N}$-(Substituted benzoylamino)-5-carbethoxymethyl1,2,3,6-tetrahydropyridines as Potential Anti-inflammatory and Hyperglycemic Agents. Med Chem Res. 1999; 9(2): 133-148.

14. Yoon K, Wilson T, Williams S, Redda K. Synthesis and Pharmacological Evaluations of $\mathrm{N}$-(substituted benzoylamino)-5-carbethoxymethyl1,2,3,6-tetrahydropyridines as Potential Antiinflammatory Agents. Drugs Exp Clin Res. 2000; 26(3): 73-82.

15. Yoon K, Kode B, Bowen L, Redda K. Synthesis of N-(Substituted Phenylcarbonylamino)-4-ethyl-1,2,3,6-tetrahydropyridines as Potential Nonsteroidal Anti-inflammatory Agents. J Heterocycl Chem. 2001; 38: 6976. doi: $10.1002 /$ jhet.5570380110 
16. Mochona B, Redda KK. Synthesis of N-benzoylamino-1,2,3,6-tetrahydropyridine derivatives as potential anti-inflammatory agents. J Heterocycl Chem. 2007; 44(6): 1383-1387. doi: 10.1002/jhet.5570440622

17. Gangapuram M, Redda KK. Synthesis of Substituted N-[4(5-Methyl/ phenyl-1,3,4-oxadiazol-2-yl)-3,6-dihydropyridin-1(2H)-yl]benzamide/ benzene Sulfonamides as Anti-Inflammatory and Anti-Cancer Agents. J Heterocycl Chem. 2009; 46(2): 309-316. doi:10.1002/jhet.62

18. Ghaffari M, Ardley T, Gangapuram M, Redda K. Synthesis of N-Substituted Carbonylamino-1,2,3,6-Tetrahydropyridines as Potential Anti-Inflammatory Agents. Synth Commun. 2011; 41(7): 2615-2623. doi:10.1080/00397911.2010 .515335

19. Molinspiration Property Calculation Service. 2017.

20. i) SYBYL-X 2.1. Tripos Intentional. USA. 2011.

ii) McGann M. OEDOCKING 3.0.1. OpenEye Scientific Software; Santa Fe, NM.

iii) McGann MR, Almond HR, Nicholls A, Grant JA, Brown FK. Gaussian

docking functions. Biopolymers. 2003; 68(1): 76-90. doi: 10.1002/bip.10207
21. Tamura Y, Minamikawa J, Ikeda M. O-mesitylenesulfonylhydroxylamine and Related compounds-Powerful Aminating Reagents. Synthesis. 1977; (1): 1-17. doi:10.1055/s-1977-24260

22. Tamura $Y$, Miki $Y$, Honda T, Ikeda M. Synthesis of 3-substituted $\mathrm{N}$-aminopyridinium salts. J Heterocycl Chem. 1972; 9(4): 865-868. doi: 10.1002/jhet.5570090418

23. Leagault C, Charette A. Highly Efficient Synthesis of O-(2,4-Dinitrophenyl) hydroxylamine. Application to the Synthesis of Substituted N-Benzoyliminopyridinium Ylides. J Org Chem. 2003; 68(18): 7119-7122. doi: 10.1021/jo034456l

24. Mu Y, Peng S, Zhang A, Wang L. Role of pocket flexibility in the modulation of estrogen receptor alpha by key residue arginine 394. Environ Toxicol Chem. 2011; 30(2): 330-336. doi: 10.1002/etc.389 